\title{
A question of colour: systemic racism in sports and exercise medicine
}

\author{
Phathokuhle Cele Zondi ㄷ, ${ }^{1}$ Ashley V Austin ${ }^{2}$
}

People often think of racism as aggressive and overt. However, more commonly it is subtle-intricately embedded into societal beliefs, expectations and practices. Systemic racism leads to the disproportionate distribution of resources, power and opportunities. ${ }^{12}$ It is ubiquitous, and exists in sports and exercise medicine (SEM) as it does in other industries. As two black SEM professionals, from different countries on different continents, it is our daily lived experience. We have had to sidestep racial slurs from patients; spar with employers over intentionally low-balled salary offers that devalue our talents; and hurdle perceptual barriers in the workplace just to be acknowledged as equals, despite occupying leadership positions. The ultimate challenge of playing in a sports medicine game that ignites us, within a system that often devalues us, is to use our efforts and voices to level the playing field for future generations.

The purpose of this editorial is to highlight distinct ways in which institutional racism manifests within SEM, and provide a glimpse into why diversity, inclusion and representation matter for the future.

\section{BLACK CLINICIANS AND RESEARCHERS REMAIN UNDER-REPRESENTED}

She enters the training room with a white coat on, all distinguishing identifiers accessible to the eye: ID badge with a 'Doctor' name tag, professional clothing and a stethoscope. 'Are you one of the trainers?' the patient asks-a familiar question. 'I'm the doctor who will be performing your physical today', she replies. 'Oh,' the athlete and her mother state, both confused and intrigued. 'I've never had a Black doctor before', the athlete continues. A sound point.

\footnotetext{
${ }^{1}$ High Performance Commission, Medical Advisory Committee, South African Sports Confederation and Olympic Committee, Houghton, South Africa ${ }^{2}$ Stadium Sports Medicine Center, University of Washington, Seattle, Washington, USA
}

Correspondence to Dr Phathokuhle Cele Zondi, High Performance Commission, Medical Advisory Committee, South African Sports Confederation and Olympic Committee, Houghton 4409, South Africa; phathokuhlez@gmail.com
Black doctors frequently encounter a reaction of surprise that a person of colour (POC) is in a position of authority. Similar to most industries, POC in SEM are still trapped in historically physically laborious, junior/midlevel roles with limited opportunity for advancement into leadership roles. ${ }^{3}$ Systemic racism restricts access and capacity for contribution by POC. ${ }^{4}$

Black doctors make up $8 \%$ of all doctors in the USA, ${ }^{3}$ where the population of black people is $13.7 \% .^{5}$ In South Africa, while black Africans are the overwhelming majority demographic at $81 \%,{ }^{6}$ they constitute only $31 \%$ of all registered medical practitioners (demographics provided in an email dated 23 October 2020 from the Registrar at the Health Professionals Council of South Africa, registrar@hpcsa.co.za). In both countries, there are currently no published diversity statistics specific to SEM, which is problematic. Anecdotally, however, POC are under-represented globally in clinical and academic SEM. Transformation in SEM research groups, scientific committees and 'thought leadership' teams has been slow, and the clear advancements in correcting gender imbalance in international structures have not yet been mirrored in relation to racial diversity.

\section{REPRESENTATION MATTERS}

In multiple industries diversity and inclusion have been associated with improved organisational growth and business performance. ${ }^{7}$ Companies that are more diverse are better able to attract and retain talent, and improve customer orientation through enhanced insights and decision-making. ${ }^{7}$ In the SEM setting, diverse teams offer a wider range of approaches and perspectives when drafting clinical protocols, research protocols and sports policy. Furthermore, diversity will enable better insights into the backgrounds, needs and motivations of all athletes thus improving patient care. Finally, representation will encourage those watching from the side lines, inspiring more POC to join the SEM profession.

We know our presence as a black physician in the training room matters. We have seen the visible guard that drops during a consultation when athletes of colour
(AOC) find out we are the physicians who will care for them. AOC have told us that they feel more comfortable when a physician shows an understanding of their social context and respect for their culture. We have had many impromptu visits from AOC with no true chief complaint, where discussions about race and isolation in our respective fields ensue. AOC can feel lonely in non-inclusive systems that do not support or acknowledge variances in their race, ethnicity or socioeconomic status.

\section{PREPARE FOR PROGRESS}

Calling out systemic discrimination and acknowledging systemic privilege are the first steps to tearing down the suffocating walls of institutional racism. Organisations that are invested in the growth and longevity of SEM should not sidestep this difficult conversation but instead strive to create environments that encourage honest conversation and progressive leadership. If the SEM community is committed to providing the best possible patient care and if we truly do love the SEM game, then we should lace up and prepare to rally, spar and slam dunk our way to a more inclusive and sustainable environment. As in any sport, sustainable success will require effective leadership, teachable players and commitment to a well-formulated game plan.

Twitter Phathokuhle Cele Zondi @phatho_z

Contributors Both authors contributed to writing, revision and approval of final editorial.

Funding The authors have not declared a specific grant for this research from any funding agency in the public, commercial or not-for-profit sectors.

Competing interests None declared.

Patient consent for publication Not required.

Provenance and peer review Not commissioned; externally peer reviewed.

(c) Author(s) (or their employer(s)) 2021. No commercial re-use. See rights and permissions. Published by BMJ.

$$
\text { (A) Check for updates }
$$

To cite Zondi PC, Austin AV. Br J Sports Med 2021;55:526-527.

Accepted 3 December 2020

Published Online First 17 December 2020

Br J Sports Med 2021;55:526-527.

doi:10.1136/bjsports-2020-103351

ORCID iD

Phathokuhle Cele Zondi http://orcid.org/0000-00016001-5966

\section{REFERENCES}

1 Altonji J, Doraszelski U, Segal L. Black/White differences in wealth. Econ Perspect 2000;24:38-50.

2 Manduca R. Income inequality and the persistence of racial economic disparities. Socio/ Sci 2018; 5:182-205. 
3 U.S Bureau of Labor Statistics. Employed persons by detailed occupation, sex, race, and Hispanic or Latino ethnicity [internet]. Washington, DC, 2020. Available: https://www.bls.gov/cps/cpsaat11.htm

4 Sian P. Microaggressions, Whiteness and the Politics of Exclusion. In: Navigating institutional racism in British universities. Cham: Palgrave Macmillan, 2019: 1-8.
5 U.S. Census Bureau. Population statistics by race [internet]. Washington, DC, 2019. Available: https:// www.census.gov/quickfacts/fact/table/US/PST045219

6 Statistics South Africa. Mid-year population estimates 2020 [internet]. Pretoria, South Africa: Isibalo House, 2020. Available: http://www.statssa.gov.za/publications/ P0302/P03022020.pdf [Accessed 2 Sept 2020].
7 Hunt V, Prince S, Dixon-Fyle S, et al. Delivering through Diversity [internet]. New York: McKinsey \& Company, 2018. Available: https://www.mckinsey.com/ /media/ mckinsey/business\%20functions/organization/our\% 20insights/delivering\%20through\%20diversity/ delivering-through-diversity_full-report.ashx [Accessed 9 Oct 2020]. 